\title{
Technical Note: Effect of Sampling Protocol on Plasma Nonesterified Fatty Acid Concentration in Dairy Cows
}

\author{
A. E. Brickner, R. R. Rastani, ${ }^{1}$ and R. R. Grummer \\ Department of Dairy Science, University of Wisconsin, Madison 53706
}

\begin{abstract}
The objective of these experiments was to determine effects of sampling protocol on plasma nonesterified fatty acid (NEFA) concentration. In experiment 1,8 nonlactating, nongestating dairy cows were blood sampled from a jugular vein catheter (basal, 0 min), moved to an exercise lot for $15 \mathrm{~min}$, returned to stanchions, and sampled immediately and at 5, 15, 30, 60, and 120 min following return to their stalls. Following $15 \mathrm{~min}$ of exercise, plasma NEFA concentration increased, peaking at $5 \min (225 \mu \mathrm{Eq} / \mathrm{L})$ and returning to basal $(84 \mu \mathrm{Eq} / \mathrm{L})$ by $30 \mathrm{~min}(110 \mu \mathrm{Eq} / \mathrm{L})$. Cows were then moved to box stalls overnight, and $24 \mathrm{~h}$ after the basal sample, they were locked up and sampled again. Housing cows in a box stall overnight and locking them in headlocks increased plasma NEFA concentration (184 $\mu \mathrm{Eq} / \mathrm{L})$. In a second experiment at a large free-stall commercial dairy, 11 late-gestation nonlactating dairy cows were locked in headlocks at feeding, blood was sampled from the coccygeal artery or vein $(0 \mathrm{~min})$, and cows were then released and allowed to finish eating and return to their stalls. Cows were then herded to headlocks and sampled immediately at $120 \mathrm{~min}$ after initial sampling and at 135, 150, and $180 \mathrm{~min}$. Plasma NEFA concentration was highest at initial lockup (0 $\min ; 284 \mu \mathrm{Eq} / \mathrm{L})$, lowest at $180 \mathrm{~min}(178 \mu \mathrm{Eq} / \mathrm{L})$, and intermediate at time points in between. A second group of 10 late-gestation nonlactating dairy cows were locked in headlocks at feeding, and blood was sampled immediately and at 5, 15, 30, and $60 \mathrm{~min}$. Plasma NEFA concentration was highest 15 min after being placed in headlocks and lowest 60 min after lockup (221 and $113 \mu \mathrm{Eq} /$ $\mathrm{L}$, respectively). At each time point in experiments 1 and 2, a behavior score was given ( 1 to $10 ; 1=$ calm; $10=$ extremely excited). In both experiments, there was a significant correlation between the plasma NEFA concentration and behavior score. In conclusion, plasma NEFA concentration was affected by sampling protocol.
\end{abstract}

Received October 16, 2006.

Accepted December 20, 2006.

${ }^{1}$ Corresponding author: rrastani@msccompany.com
Key words: nonesterified fatty acid, sampling protocol, behavior

Plasma NEFA concentration is often a key clinical measurement of energy status in dairy cows during the periparturient period. Plasma NEFA concentration varies diurnally and is more variable in early lactation (Eicher et al., 1998). Additionally, it has been documented that NEFA varies with the amount of concentrate fed (Sutton et al., 1988) and time of feeding (Blum et al., 2000; Nielsen et al., 2003). There is also a response to supplemental antilipolytic compounds, such as propylene glycol, on the reduction of plasma NEFA (Grummer et al., 1994).

The concentration of NEFA in the circulation is partially a result of adipose tissue lipolysis and is stimulated by epinephrine (Erickson et al., 1990). Therefore, the level of coercion or excitement during the act of moving cows may act to increase plasma NEFA concentration, independently of energy balance. Our objective was to determine how plasma NEFA concentration is affected by sampling protocol, including changes in cow movement and amount of coercion needed to move cows into headlocks.

In the first experiment, 8 nonlactating, nongestating Holstein cows were fitted with a single jugular vein catheter more than $24 \mathrm{~h}$ before sampling. Initially, cows were housed in a stanchion barn. On the first morning of the experimental protocol, cows were fed alfalfa hay ad libitum for $1 \mathrm{~h}$ every $2 \mathrm{~h}$ (0400, 0600, 0800, 1000, and $1200 \mathrm{~h}$ ). Cows were then moved to box stalls (2 cows/stall) and fed alfalfa hay ad libitum at $1500 \mathrm{~h}$ and the following day at 0600 and $0800 \mathrm{~h}$. At approximately $0900 \mathrm{~h}$ on $\mathrm{d} 1$, a blood sample was taken via a jugular vein catheter by a single researcher to obtain a basal sample from each cow while lying down. At $0945 \mathrm{~h}$ on d 1, 7 researchers entered the barn, made the cows stand up (procedure 1), and a second blood sample was taken to mimic the typical situation in which animals are blood sampled for research. Cows were left alone in the barn for approximately $1 \mathrm{~h}$, allowing them to return to the basal level of excitement. A second basal sample was taken at approximately $1130 \mathrm{~h}$ on $\mathrm{d} 1$ by 
a single researcher. At $1200 \mathrm{~h}$ on d 1, researchers entered the barn and released the cows to an outside concrete paddock to exercise for 15 min (procedure 2), where the cows were not allowed to lie down. After 15 min, the cows were moved back to their stanchions and blood samples were taken immediately and at 5,15 , 30,60 , and $120 \mathrm{~min}$. At approximately $1500 \mathrm{~h}$ on d 1 , cows were moved to box stalls with free access to feed and water and kept there overnight (procedure 3). At $0900 \mathrm{~h}$ on $\mathrm{d} 2$, a single researcher attempted to get a basal sample from each cow while it was lying down in a box stall. Obtaining the basal sample was unsuccessful, so the blood sample obtained at $0900 \mathrm{~h}$ on $\mathrm{d} 1$ when cows were lying in stanchions was considered the basal sample. At $0945 \mathrm{~h}$ on d 2, 3 researchers entered each box stall and put each cow into a headlock and sampled it at $1000 \mathrm{~h}$.

A second experiment was conducted at a large commercial dairy farm using nonlactating dairy cows between 255 and $265 \mathrm{~d}$ bred and approaching their second or greater lactation. The objective was to monitor plasma NEFA concentration after cows were pushed up into headlocks within a pen either at the time of feeding, which required very little coercion, or $2 \mathrm{~h}$ after the time of feeding, which required more coercion. Cows were housed in a 6-row free-stall barn with headlocks at the feed bunk and were fed a TMR at approximately $1040 \mathrm{~h}$. Immediately after feeding, researchers entered the barn, locked the headlocks, and sampled blood from 21 cows (time $=0$ ). Eleven of the cows were released from the headlocks (procedure A). Ten cows remained in headlocks, and additional samples were obtained at $5,15,30$, and 60 min (procedure B). After the 60-min sample, the headlocks were unlocked. Cows were allowed to finish eating and return to their stalls. At 1240 $\mathrm{h}$, the 11 cows used for procedure A were relocked in headlocks and blood was sampled immediately and at 15,30 , and 60 min following the second lockup. Cows were then released from the headlocks.

At each sampling, researcher, time of sample, and behavioral score ( 1 to 10 , with 1 = sedate, normal rumination, or sleeping, 2 = head up and looks alert with perked ears, $3=$ ears back or twitching, $4=$ swishing tail or shaking head, $5=$ lifting feet, $6=$ swaying back and forth, 7 = kicking, $8=$ bawling or salivating, $9=$ jumping, and $10=$ extreme response, causing harm to itself) was recorded. If a cow exhibited more than one behavioral score, the score was assigned by the highest numerical response. The behavioral score was recorded to determine whether there was a relationship between behavioral stress and plasma NEFA concentration. Blood was collected in Vacutainer tubes containing EDTA (Becton Dickinson, Franklin Lakes, NJ), placed on ice, centrifuged $\left(1,430 \times g\right.$ for $15 \mathrm{~min}$ at $\left.4^{\circ} \mathrm{C}\right)$, and plasma was harvested for analysis of NEFA concentration (NEFA-C, Wako Fine Chemical Industries USA, Dallas, TX; Johnson and Peters, 1993).

Data were analyzed as repeated measures using the mixed models procedure of SAS (SAS Institute, 1999). The model included a fixed effect of time and a random effect of cow. The compound symmetry covariance structure was used. Least squares means and standard errors of the mean are reported. Significance was declared at $P<0.05$ after adjustment by the TukeyKramer method for preventing a type II error when comparing means. Correlation of the plasma NEFA concentration and behavior score was determined by the Spearman test within the correlation procedure of SAS (SAS Institute, 1999).

Simulating a typical research-sampling situation, in which cows are prompted to stand up from a lying position, did not significantly increase plasma NEFA concentration $(111 \mu \mathrm{Eq} / \mathrm{L}$ for baseline to $120 \mu \mathrm{Eq} / \mathrm{L}$ following standing; procedure 1). Following $15 \mathrm{~min}$ in the exercise lot (procedure 2), plasma NEFA concentration increased upon returning to stanchions in the barn and did not return to basal levels for 30 min (Figure 1; $P<$ 0.05 ). After approximately $19 \mathrm{~h}$ of free roaming in a box stall and then being placed in a headlock (procedure 3 ), plasma NEFA concentration was significantly elevated from a basal value of 84 to $184 \mu \mathrm{Eq} / \mathrm{L}(P<0.001)$. For all procedures in experiment 1 , the behavior score increased as plasma NEFA concentration increased ( $P$ $<0.001 ; \mathrm{r}=0.52$ ).

The 8 cows used for experiment 1 had previously been used in a $4 \times 4$ Latin square experiment and had been handled extensively by researchers during the previous 5 mo. Despite this, plasma NEFA concentration increased over $150 \%$ from basal to 5 min following return to stanchions from the exercise lot. We conducted experiment 2 on a commercial dairy herd to monitor plasma NEFA concentration during sampling protocols typically used by a veterinarian or consultant.

Procedures in experiment 2 were aimed at monitoring plasma NEFA concentration while cows were moved into headlocks within a pen, either at the time of feeding, which required very little coercion, or $2 \mathrm{~h}$ after the time of feeding, which required more coercion. Although a statistical comparison was not made, the change in NEFA from 15 min following lockup to 60 min following lockup followed a similar trend for both procedures, with plasma NEFA decreasing by $75 \mu \mathrm{Eq} / \mathrm{L}$ for procedure $\mathrm{A}$ and $107 \mu \mathrm{Eq} / \mathrm{L}$ for procedure $\mathrm{B}$. For cows undergoing procedure A, plasma NEFA concentration was highest at initial lockup $(284 \mu \mathrm{Eq} / \mathrm{L} ; 0 \mathrm{~min})$, lowest 60 min following the second lockup (180 min after initial lockup; $178 \mu \mathrm{Eq} / \mathrm{L}$ ), and intermediate at time points in between (Figure $2 ; P<0.05$ ). When cows were sampled 


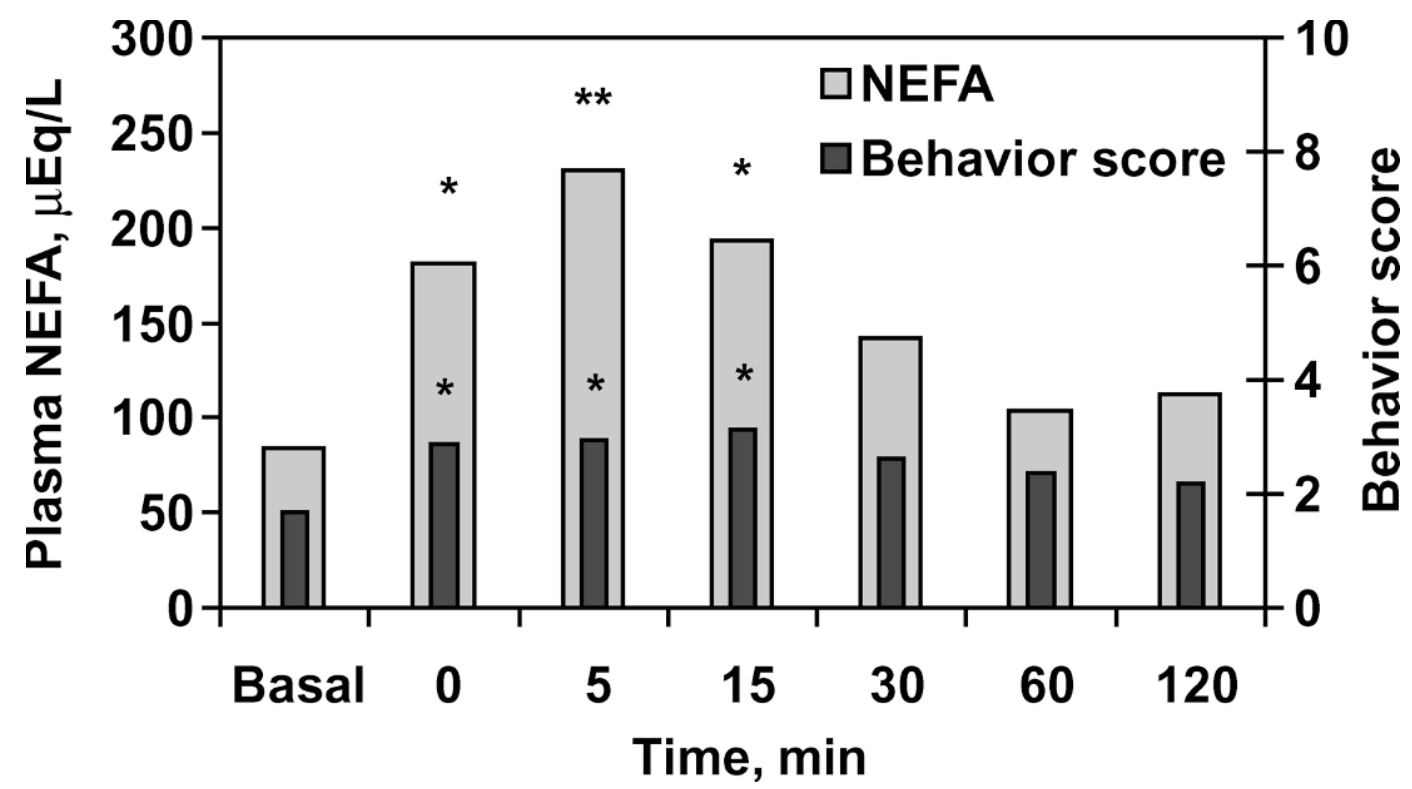

Figure 1. Plasma NEFA concentration and behavior score of cows lying in a stanchion (basal) and at various time points after being returned to stanchions following release outside for $15 \mathrm{~min}$ of exercise (experiment 1, procedure 2). Data are expressed as least squares means. Standard errors of the mean for the plasma NEFA concentration and behavior score are 26.31 and 0.27 , respectively. Different from basal at $P<0.001(* *)$ and $P<0.05(*)$.

following lockup in procedure B, plasma NEFA concentration was highest 15 min after being placed in headlocks and lowest $60 \mathrm{~min}$ after lockup (221 and $113 \mu \mathrm{Eq} /$ $\mathrm{L}$, respectively; $P<0.05$; Figure 3 ). In procedures $A$ and $B$, plasma NEFA concentration was greater after initial lockup (0 and $120 \mathrm{~min}$, respectively) compared with later time points (60 min later). In experiment 2 , there was a significant correlation between the plasma NEFA concentration and behavior score $(\mathrm{r}=0.32, P<0.02$, and $\mathrm{r}=0.33, P<0.03$, for procedure $\mathrm{A}$ and $\mathrm{B}$, respectively). In conclusion, plasma NEFA concentration was affected by sampling protocol. However, changes in NEFA

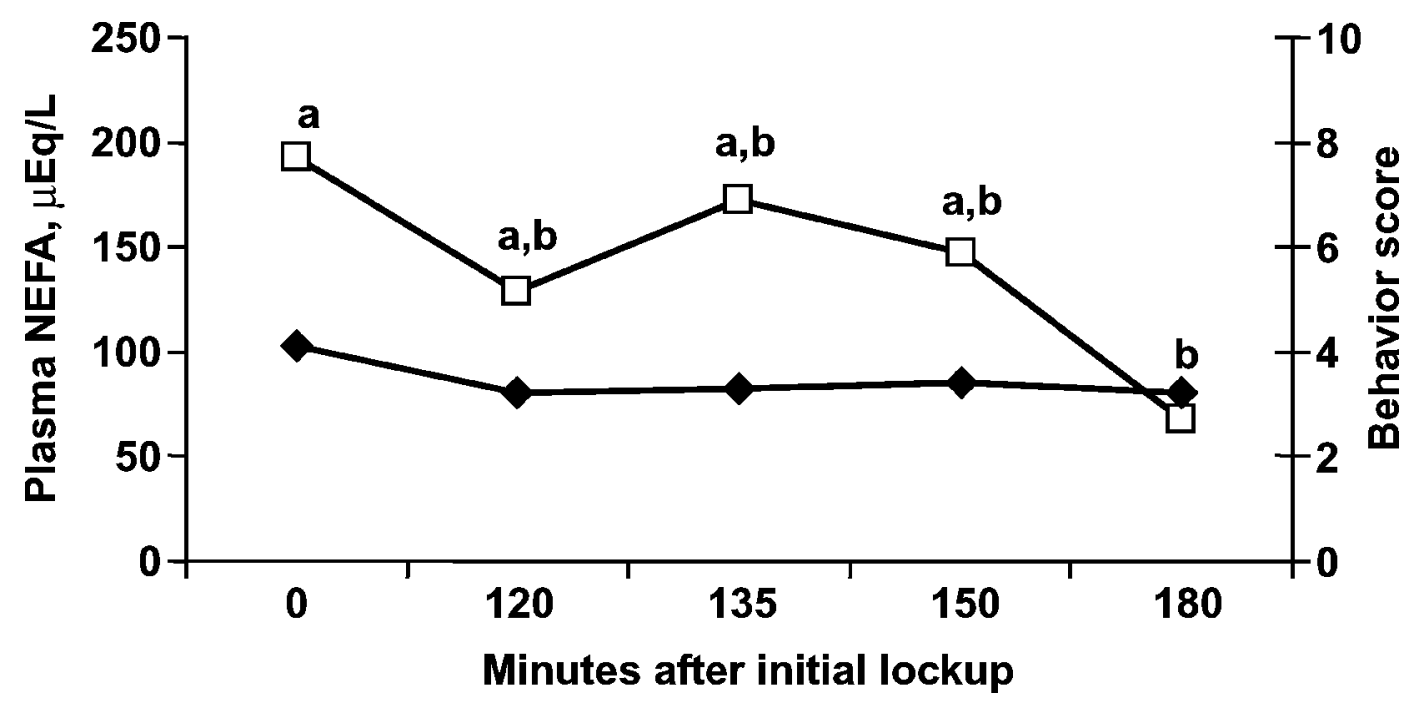

Figure 2. Behavior score $(\diamond)$ and mean plasma NEFA concentrations $(\square)$ of cows that were locked up at feeding and immediately sampled for blood (time 0), released after sampling, moved back into headlocks approximately $2 \mathrm{~h}$ later, and sampled immediately (time 120) and at 15 (time 135), 30 (time 150), and 60 (time 180) min following the second lockup (experiment 2, procedure A). Data are expressed as least squares means. Standard errors of the mean for plasma NEFA concentration and behavior score are 20.8 and 0.44 , respectively. Means with different letters differ at $P<0.05$. 


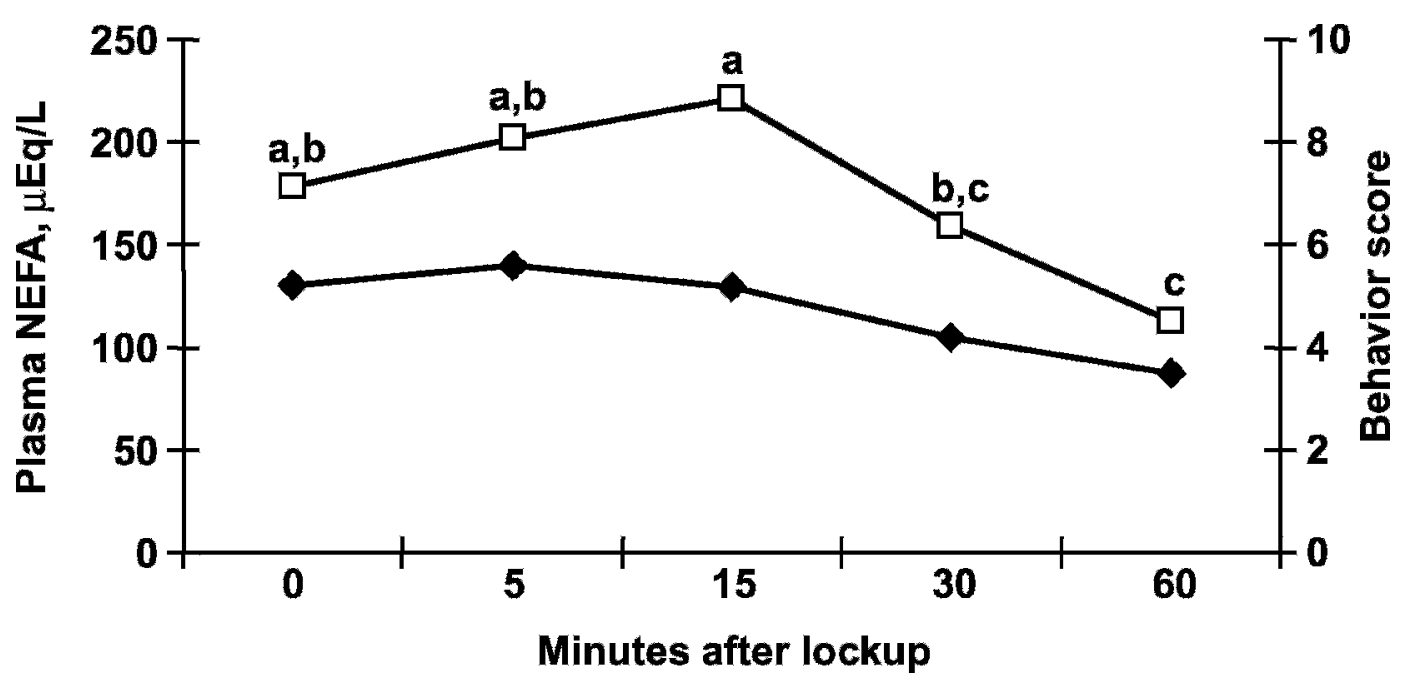

Figure 3. Plasma NEFA concentration $(\square)$ and behavior score $(\bullet)$ of cows after placement in headlocks at time of feeding and through 60 min after feeding (experiment 2, procedure B). Data are expressed as least squares means. Standard errors of the mean for the plasma NEFA concentration and behavior score are 20.8 and 0.44 , respectively. Means with different letters differ at $P<0.05$.

concentration appeared to show a similar pattern of an initial increase after cow movement and a decrease of $30 \mathrm{~min}$ for cows in a tie-stall facility and $60 \mathrm{~min}$ for cows in a free-stall facility, regardless of the level of coercion. This should be considered when interpreting plasma NEFA concentrations as an indicator of metabolic status in clinical or research settings.

\section{ACKNOWLEDGMENTS}

We would like to thank Hubbard Feeds, MSC Specialty Nutrition, Monsanto Co., Pioneer Hi-Bred International, Inc., Vita Plus Corporation, and West Central Cooperative for providing financial support for this experiment. We would also like to thank Holsum Farm for the cows and facilities, and Matias Aguerre, Tanya Gressley, Jose Pires, Noelia Silva del Rio, and Rick Watters for sampling assistance.

\section{REFERENCES}

Blum, J. W., R. M. Bruckmaier, P. Y. Vacher, A. Mnger, and F. Jans. 2000. Twenty-four hour patterns of hormones and metabolites in week 9 and 19 of lactation in high-yielding dairy cows fed triglycerides and free fatty acids. J. Vet. Med. 47:43-60.

Eicher, R., A. Liesegang, E. Bouchard, and A. Tremblay. 1998. Influence of concentrate feeding frequency and intrinsic factors on diurnal variations of blood metabolites in dairy cows. Bovine Proc. 31:198-202.

Erickson, P. S., A. M. Trusk, and M. R. Murphy. 1990. Effects of niacin source on epinephrine stimulation of plasma nonesterified fatty acid and glucose concentrations, on diet digestibility and on rumen protozoal numbers in lactating dairy cows. J. Nutr. 120:1648-1653.

Grummer, R. R., J. C. Winkler, S. J. Bertics, and V. A. Studer. 1994. Effect of propylene glycol dosage during feed restriction on metabolites in blood of prepartum Holstein heifers. J. Dairy Sci. 77:3618-3623.

Johnson, M. M., and J. P. Peters. 1993. Technical note: An improved method to quantify nonesterified fatty acids in bovine plasma. J. Anim. Sci. 71:753-756.

Nielsen, N. I., K. L. Ingvartsen, and T. Larsen. 2003. Diurnal variation and the effect of feed restriction on plasma and milk metabolites in TMR-fed dairy cows. J. Vet. Med. A Physiol. Pathol. Clin. Med. 50:88-97.

SAS Institute. 1999. User's Guide: Statistics. Version 8 Edition. SAS Institute, Cary, NC.

Sutton, J. D., I. C. Hart, S. V. Morant, E. Schuller, and A. D. Simmonds. 1988. Feeding frequency for lactating cows: Diurnal patterns of hormones and metabolites in peripheral blood in relation to milk-fat concentration. Br. J. Nutr. 60:265-274. 